\title{
The night and day of dung beetles (Coleoptera, Scarabaeidae) in the Serra do Japi, Brazil: elytra colour related to daily activity
}

\author{
Malva Isabel Medina Hernández ${ }^{1}$
}

\begin{abstract}
In the present study 387 dung beetles (Coleoptera: Scarabaeidae) were surveyed at the Serra do Japi, in the Atlantic Forest in São Paulo State, with four baited pitfall traps during the months of December, 1998, and January, 1999 during eight 24 hour cycles. A total of 30 species were identified and temporal variation in activity patterns among the species shows a specialization in the use of food resources: 9 species were classified as nocturnal and 13 as diurnal. The daily activity pattern of dung beetles does not necessarily correspond to the taxonomic classification, but is strongly related to the colouring of species, determined by predominant elytra colour: nocturnal species have $89 \%$ more chances of being black as opposed to colourful. Black nocturnal species might have evolved as an interspecific adaptation to avoid predation (cryptic colouring). Among the colourful diurnal dung beetles, measure of body length of each species shows that development of bright colouring was more often found in medium to large species, which suggests that colouring evolved as a response to intraspecific pressures, important in agonistic encounters among males.
\end{abstract}

KEYwords. Coleoptera; colour; daily activity; dung beetles; Scarabaeidae.

\section{INTRODUCTION}

In terrestrial animals, colours are especially found in animals such as insects and birds. Both groups have highly developed visual systems and frequently interact with each other, this interaction being most by predation of insects by birds. Colour in these animals is typically associated with a diurnal behavioural pattern, which renders the hypothesis that colour may be an adaptation used for inter and intraspecific communications (Otronen 1988; ENDLER 1990). As a form of interspecific communication, colour in insects has been associated with the evolution of defence against predators, being either cryptic coloration or aposematic coloration. Cryptic coloration, or camouflage, is a coloration that resembles the substrate, making the animal hard to pinpoint by its potential predators. On the other hand, the development of brilliant and conspicuous colouring is called aposematic colouring, and is a form of signaling impalatability, usually evolved as a defence by prey animals (Guilford 1990). As a form of intraspecific communication, colours are used to send visual cues to individuals of the same sex, as in the case of agonistic interaction among males, or to individuals of the opposite sex, such as in courtship and mating.

In beetles, the most frequent colour among diurnal species is green, but blue, red, yellow, and purple can also be common. Since a species colour is usually the evolutionary result of the animals' interaction in its ecological niche, among beetles, a brown colouring is interpreted as a neutral (selection wise) colour, since this colour is usually found in dwellers species. Nocturnal species of beetles are typically black, which is considered favourable for such a behavioural pattern (CROwSON 1981).

Among the Coleoptera, the family Scarabaeidae sensu stricto has approximately 5000 species, and little is known about the biology and ecology of most species of the rich South American fauna (VAZ-DE-MeLLo 2000). Brilliant and metallic colouring is common in this family (HALFFTER \& MATTHEWS 1966; HALfTter \& Edmonds 1982; Young 1984), but there is still no consensus if colours correspond to aposematism or are used for intraspecific communications (VULINEC 1997). It has been argued that the partitioning of resources among the species of this family is based on the different modes of habit utilization, with differences between species in macrohabitat selection, feeding habit, seasonality and also daily behavioural patterns, i.e. diurnal vs. nocturnal (HALFFTER \& MATTHEWs 1966; HALFTTER \& EdMONDS 1982; HANSKI 1991; HANSKI \& CAMBEFORT 1991; HALFTter et al. 1992). In fact, the daily activity patterns for insects in this family have been recorded for many species, but

1. Instituto de Biociências, Campus de Rio Claro, Universidade Estadual Paulista. Rio Claro-SP, Brazil Actual address: Departamento de Sistemática e Ecologia, Centro de Ciências Exatas e da Natureza, Universidade Federal da Paraíba. 58051-900 João Pessoa-PB, Brazil. E-mail: malvamh@yahoo.com 
Table 1. Daily activity and elytra predominant colouring in dung beetles (Coleoptera: Scarabaeidae) from Serra do Japi.

\begin{tabular}{|c|c|c|c|}
\hline SUBFAMILY & SPECIES & ACTIVITY & COLOUR \\
\hline \multirow[t]{13}{*}{ Coprinae } & Ateuchus histrio (Balthasar, 1939) & - & Black \\
\hline & Canthidium trinodosum (Bohenann, 1858) & Diurnal & Black \\
\hline & Canthidium sp.1 & - & Black \\
\hline & Canthidium sp. 2 & Diurnal & Brown \\
\hline & Dichotomius assifer (Eschscholtz, 1822) & Nocturnal & Black \\
\hline & Dichotomius depressicollis (Harold, 1867) & Nocturnal & Black \\
\hline & Dichotomius mormon (Ljungh, 1799) & Nocturnal & Black \\
\hline & Ontherus azteca Harold, 1869 & - & Black \\
\hline & Trichillum $\mathbf{s p .}$ & - & Brown \\
\hline & Uroxys aterrima Harold, 1867 & Nocturnal & Black \\
\hline & Uroxys lata Arrow, 1933 & Nocturnal & Black \\
\hline & Uroxys kratochvili Balthasar, 1940 & Nocturnal & Black \\
\hline & Uroxys sp. & Black & Black \\
\hline \multirow[t]{4}{*}{ Eurysterninae } & Eurysternus cyanescens Balthasar, 1939 & Diurnal & Blue \\
\hline & Eurysternus hirtellus Dalman, 1824 & - & Brown \\
\hline & Eurysternus parallelus Laporte, 1840 & Diurnal & Brown \\
\hline & Eurysternus sp. & Diurnal & Yellow \\
\hline \multirow[t]{2}{*}{ Onitinae } & Phanaeus splendidulus (Fabricius, 1781) & Diurnal & Green \\
\hline & Coprophanaeus saphirinus (Sturm, 1826) & Diurnal & Blue \\
\hline Onthophaginae & Onthophagus sp. & - & Brown \\
\hline \multirow{10}{*}{ Scarabaeinae } & Canthon latipes Blanchard, 1843 & Diurnal & Green \\
\hline & Canthon sp. & Diurnal & Black \\
\hline & Canthonella sp. & Diurnal & Brown \\
\hline & Deltochilum furcatum (Laporte, 1840) & Nocturnal & Black \\
\hline & Deltochilum morbillosum Burmeister, 1848 & - & Black \\
\hline & Deltochilum brasiliense (Laporte, 1840) & Nocturnal & Green \\
\hline & Deltochilum rubripenne (Gory, 1831) & Diurnal & Red \\
\hline & Paracanthon pereirai d'Andretta \& Martínez, 1957 & Diurnal & Black \\
\hline & Scybalocanthon nigriceps (Harold, 1868) & Diurnal & Yellow \\
\hline & Sylvicanthon foveiventre (Schmidt, 1920) & Nocturnal & Black \\
\hline
\end{tabular}

this is the first account for several neotropical species. In this study, the daily activity pattern was determined for dung beetles species of the Serra do Japi and the association between activity pattern and coloration of the species was assessed.

\section{MATERIAL AND METHODS}

The study was carried out at Serra do Japi, located at $23^{\circ}$ $14^{\prime} \mathrm{S}$ and $46^{\circ} 57^{\prime} \mathrm{W}$. The $354 \mathrm{~km} 2$ area is located in the Atlantic Forest in the State of São Paulo, with altitudes ranging from 700 to $1300 \mathrm{~m}$ and annual average temperature from $19.2^{\circ} \mathrm{C}$ in lowest places to $15.7^{\circ} \mathrm{C}$ in highest one; rainfall averages vary between $1907 \mathrm{~mm}$ and $1367 \mathrm{~mm}$ a year, with predominant rains in December and January (PINTO 1992). Semidesciduous forests occupy the greater part of the Serra, with leaf fall during winter; the tree's height varies between 20 to $25 \mathrm{~m}$, presenting a high diversity species (LEITÃo-FILHO 1992).
The insects were collected by baited pitfall traps, each one made out of a plastic container $(17 \mathrm{~cm}$ diameter and $12 \mathrm{~cm}$ deep), containing a $2 \%$ solution of detergent in water. As bait approximately $10 \mathrm{~g}$ of child excrement was used, placed in a plastic cup held over the solution. A plastic plate mounted on a wire structure was set over each trap as protection from rain.

During December 1998 and January 1999 four traps were set in the forest at two known areas of high species diversity (HERNÁNDEZ 2001), collecting insects during two $24 \mathrm{~h}$ cycles. Six more cycles of experiments were performed during December 1999. Insects were collected in four periods during a $24 \mathrm{~h}$ cycle to establish the behaviour of the species: before sunrise, after sunrise, at dusk and after dark.

Species were identified by Fernando Vaz-de-Mello (Universidade Federal de Lavras, Minas Gerais). A species was classified as diurnal or nocturnal if the majority of its individuals were collected in one of the periods. The colour of each species 


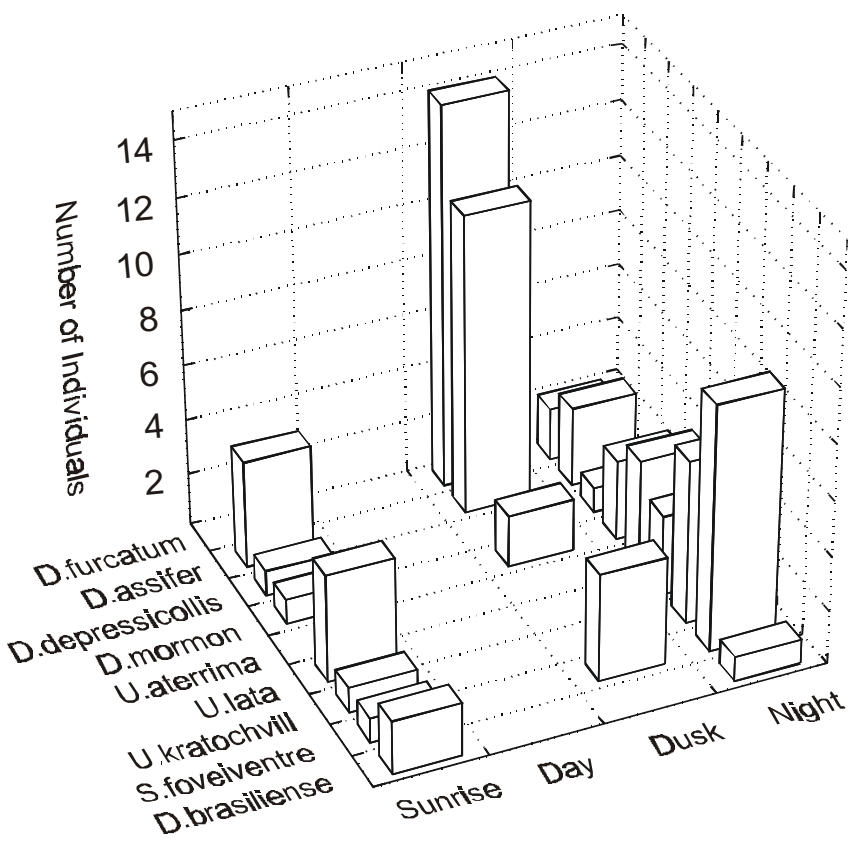

Fig. 1. Frequency histogram of daily activity of nocturnal dung beetles species from Serra do Japi.

was determined by the main colouring of the elytra, defined by direct observation at the time of collection. The measure of body length of each species was determined by the mean distance between the head extremity and the abdomen extremity (Hernández 2001). Data analysis was carried out using the software "Statistica for Windows" (STATSOFt 1998) and a chisquare test was used for testing independence among data.

\section{RESULTS AND DISCUSSION}

A total of 387 dung beetles were captured, with 30 species identified (Table 1). The temporal variation in the dung beetle community during a $24 \mathrm{~h}$ period showed a partition in the use of food resources between diurnal and nocturnal species. The frequency of captured individuals collected in each period allowed us to identify a pattern of daily activity in 22 species, 9 of which were nocturnal (Fig. 1) and 13 diurnal (Fig. 2).

The daily activity pattern of dung beetles did not necessarily correspond to the taxonomic classification at the level of subfamily or genera; even congeneric species had distinct daily activities. For instance, genera from the subfamily Coprinae with nocturnal (Dichotomius and Uroxys) and diurnal (Canthidium) activity were found. In the subfamily Scarabaeinae the genus Deltochilum had diurnal and nocturnal species, while the genus Canthon comprises only diurnal species. On the other hand, all species from subfamilies Eurysterninae and Onitinae were diurnal (Table 1).

When comparing daily activity with the predominant elytra colour of each species, a trend of colourful diurnal and black nocturnal beetles emerged (Table 1). To test this hypothesis we used a chi-square test for the 22 species, grouping them in a contingency table as diurnal or nocturnal, and black or coloured. The significant association between colour and daily pattern of activity $\left(\chi^{2}=9.21 ; \mathrm{n}=1 ; \mathrm{p}<0.01\right)$ shows that diurnal dung beetles are preferentially colourful and nocturnal dung beetles are preferentially black, as nocturnal ones have $89 \%$ more chances of being black than colourful.

Among the captured species there were insects of a wide range of sizes in both groups, nocturnal and diurnal, although the bigger species were all nocturnal (Fig. 3). When comparing daily activity pattern and body length of the 22 species it was observed that although there is a tendency for the diurnal dung beetles to be colourful and the nocturnal beetles to be black, colour (other than black or brown) is only present in species with a body length equal to or bigger than one centimetre. The three black diurnal species collected (Canthon sp., Paracanthon pereirai and Canthidium trinodosum) are all smaller than $0.7 \mathrm{~cm}$ (Fig. 3).

If we interpret species with a brown colouring as colourless, as explained above, we notice that species with a brown colouring were all found to be diurnal (Fig. 3). This result reinforces the idea that a black colouring evolved as an adaptation to nocturnal activity, which could minimize predation pressure by nocturnal animals.

These results suggest that the development of brilliant colouring on the body of diurnal dung beetles has been favoured by evolution in intraspecific encounters in species of medium and large sizes. It is possible that the lack of conspicuous colouring in smaller species or black colouring represent camouflage, defending small insects against predation. Therefore, the colouring of diurnal species does not appear to be related to aposematism, otherwise the characteristic should be widespread in the group, including the smaller species. It is plausible to attribute the adult

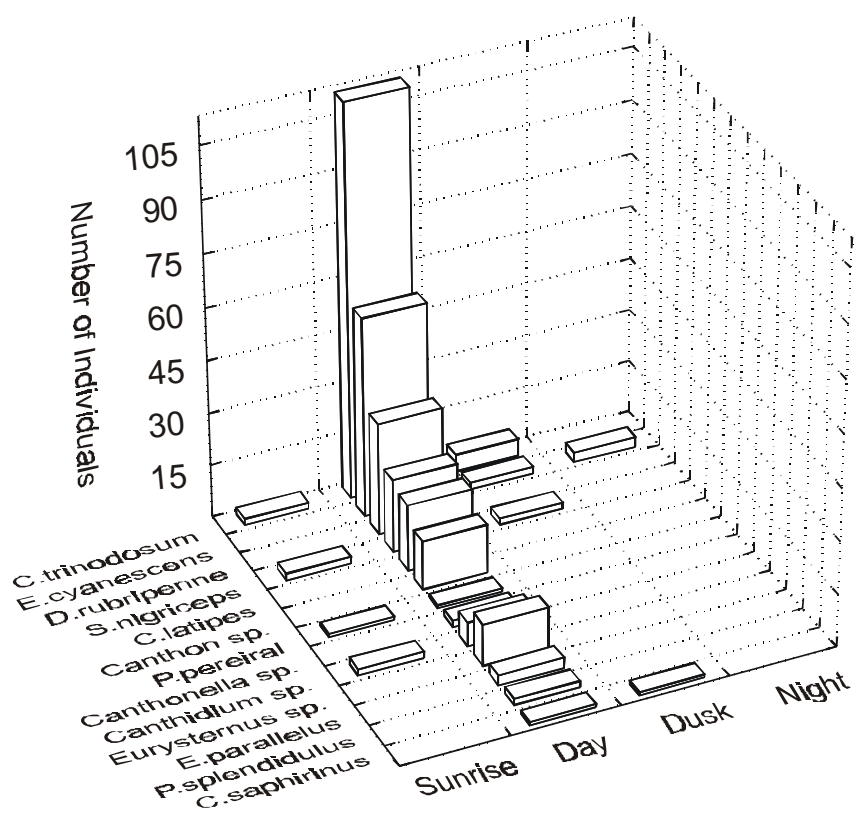

Fig. 2. Frequency histogram of daily activity of diurnal dung beetles species from Serra do Japi. 
Fig. 3. Relation between daily activity, body size and colouration in dung beetles species from Serra do Japi.

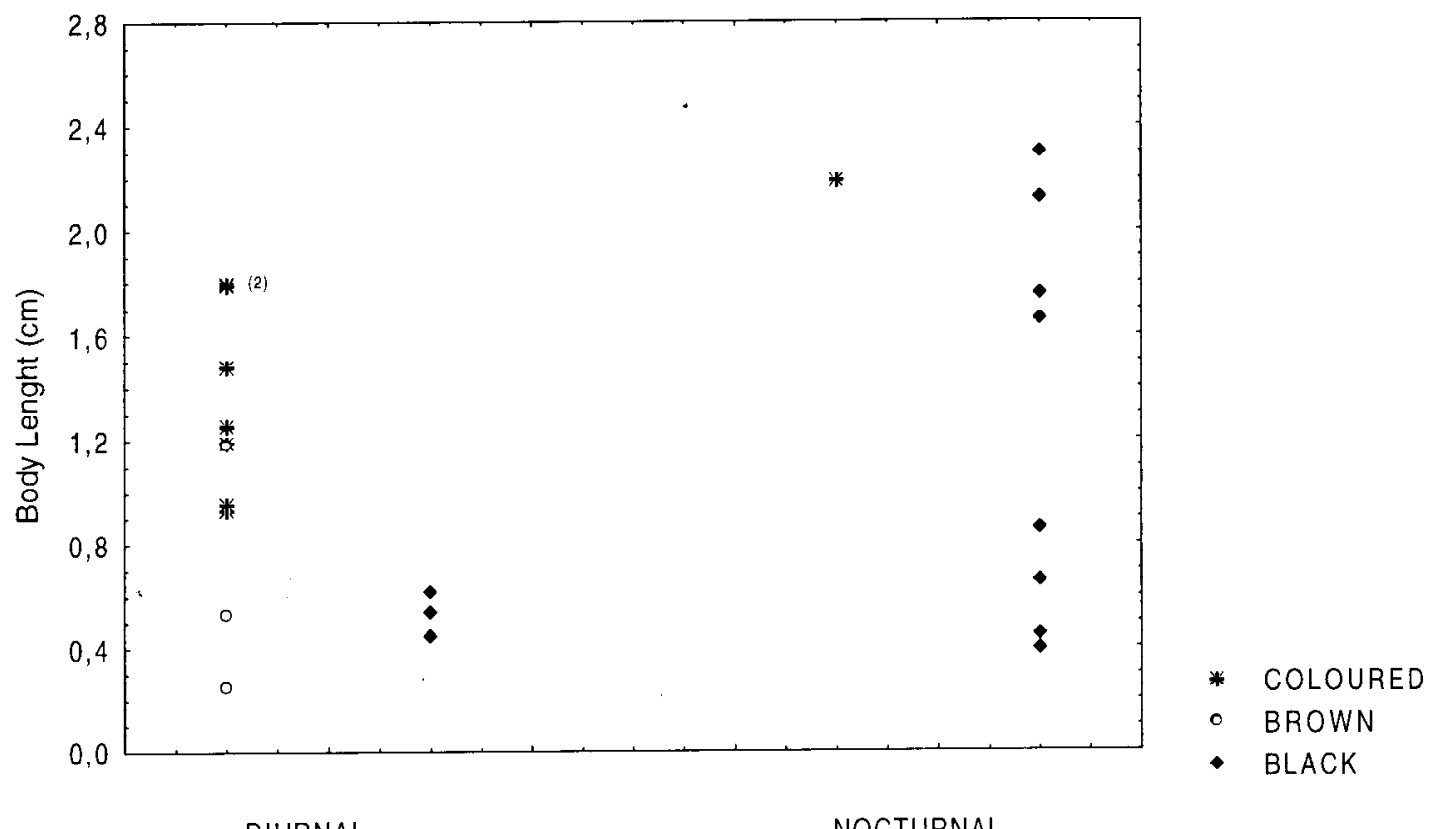

DIURNAL

NOCTURNAL

Daily Activity

colouring of the diurnal species to sexual selection related to an intraspecific behaviour, like mating or even more to agonistic encounters, which are specially important among species with medium and large body size.

Acknowledgments. I would like to thank Dr. Sérgio Furtado dos Reis for supervising my doctoral dissertation, Fernando Vaz-de-Mello for the identification of species, Dr. Woodruff Benson and Dr. Marcelo Mattos for technical recommendations on the capture methods, Naiara S. Pinto for helping in fieldwork and Anders G. da Silva for helping with the translation of the manuscript. The Secretaria Municipal de Educação de Jundiaí allowed the development of the study at the Serra do Japi and CNPq (Conselho Nacional de Desenvolvimento Científico e Tecnológico) granted me a graduate fellowship.

\section{REFERENCES}

Crowson, R. A. 1981. The Biology of the Coleoptera. New York, Academic Press, 802 p.

ENDLER, J. A. 1990. On the measurement and classification of colour in studies of animal colour patterns. Biological Journal of the Linnean Society 41: 315-352

Guilford, T. 1990. The Evolution of Aposematism, p. 23-61. In: D. L. Evans \& J. O. Schmidt (eds.). Insect Defenses. Adaptive Mechanisms and Strategies of Prey and Predators. Albany, State University of New York Press, $482 \mathrm{p}$.

Halffter, G. \& E. G. Matthews. 1966. The natural history of dung beetles of the subfamily Scarabaeinae (Coleoptera, Scarabaeidae). Folia Entomológica Mexicana 12/14: 1-312.

Halffter, G. \& W. D. Edmonds. 1982. The Nesting Behavior of Dung Beetles (Scarabaeinae): An Ecological and Evolutive Approach. México, Instituto de Ecología, 176 p.
Halffter, G.; M. E. Fávila \& V. Halffter. 1992. A comparative study of the structure of the scarab guild in mexican tropical rain forest and derived ecosystems. Folia Entomológica Mexicana 84: 131-156.

Hanski, I. 1991. The Dung Insect Community, p. 5-21. In: I. Hanski \& Y. Cambefort (eds.). Dung Beetle Ecology. Princeton, Princeton University Press, $481 \mathrm{p}$.

Hanski, I. \& Y. CAMBEFoRt. 1991. Resource Partitioning, p. 330-349. In: I. Hanski \& Y. CAmbefort (eds.). Dung Beetle Ecology. Princeton, Princeton University Press, $481 \mathrm{p}$.

Hernández, M. I. M. 2001. Morfometria de Besouros Escarabeídeos (Coleoptera: Scarabaeidae) de uma Comunidade de Floresta Atlântica. Tese de Doutorado. Instituto de Biociências, UNESP, Rio Claro, $130 \mathrm{p}$.

Leitão-Filho, H. F. 1992. A flora arbórea da Serra do Japi, p. 40-62. In: L. P. C. Morellato (org.). História Natural da Serra do Japi: Ecologia e Preservação de uma Área Florestal no Sudeste do Brasil. Campinas, UNICAMP/ FAPESP, $321 \mathrm{p}$.

OtRonen, M. 1988. Intra- and intersexual interactions at breeding burrows in the horned beetle, Coprophanaeus ensifer. Animal Behaviour 36: 741-748.

Pinto, H. S. 1992. Clima da Serra do Japi, p. 30-38. In: L. P. C. Morellato (org.). História Natural da Serra do Japi: Ecologia e Preservação de uma Área Florestal no Sudeste do Brasil . Campinas, UNICAMP/ FAPESP, $321 \mathrm{p}$.

Statsoft, Inc. 1998. Statistica for Windows. Tulsa.

VAZ-DE-Mello, F. Z. 2000. Estado atual de conhecimento dos Scarabaeidae s. str. (Coleoptera: Scarabaeoidea) do Brasil, p. 183-195. In: F. MARTínPiera; J. J. Morrone \& A. Melic (eds.). Hacia un Proyecto CYTED para el Inventario y Estimación de la Diversidad Entomológica en Iberoamérica: PrIBES-2000 vol. 1. Zaragoza, SEA.

Vulinec, K. 1997. Iridescent dung beetles: a different angle. Florida Entomologist 80: 132-141.

YounG, O. P. 1984. Perching of neotropical dung beetles on leaf surfaces: An example of behavioural termoregulation? Biotropica 16: 324 327 .

Received in 08.XI.2001; accepted in 11.XI.2002 